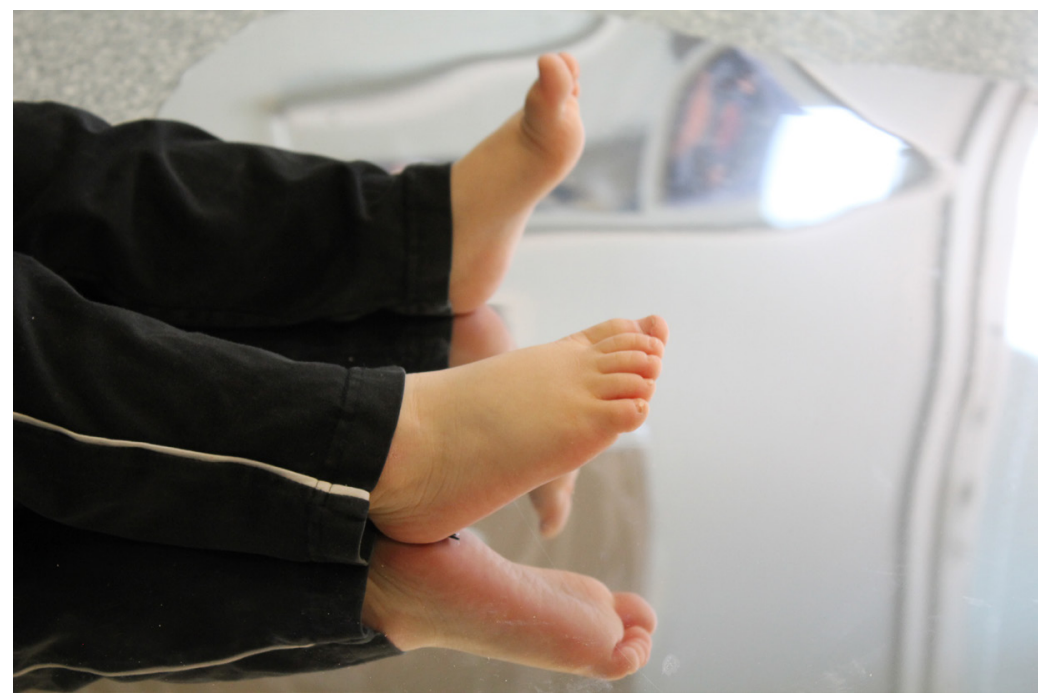

Bild 1. Barnfot. Copyright författaren, delas med CC BY-licens.

\title{
Estetiska ämnesdidaktiska rum
}

Ebba Theorell

'Perception kan ses som en ekologisk, komplex, multimodal händelse snarare än som en ström mentala handlingar. Vi behöver inte fråga vad som finns i huvudet utan tvärtom vad huvudet befinner sig i.' ${ }^{\text {' }}$

Hur du refererar till det här kapitlet:

Theorell, E. 20I8. Estetiska ämnesdidaktiska rum. I: von Schantz, U., Thorgersen, K. and Lidén, A. (red.) De estetiska ämnenas didaktik Utmaningar, processer och protester. Pp. I49-I60. Stockholm: Stockholm University Press. DOI: https://doi.org/Io.I6993/bap.j. License: CC-BY 
I samma sekund som jag kliver in i en skola händer det något i min kropp. I entrén hänger varningsskyltar för hårlöss, brand och springmask. Klassrum och korridorer är inredda med lättavtorkade och oömtåliga material; plåt, trä och plast. Ljudet en blandning av kroppar och röster som rör sig mellan dem. Färgsymfonin går i grått, beige och brunt och om det finns fönster är de vanligtvis försedda med lås. Skolgårdar är för det mesta ödsliga standardiserade, asfalterade tävlingsfält där erbjudanden står mellan att vinna i bandy, slå ut varandra på en Kingplan eller att klättra högst i en klätterställning. Sammantaget försätter alla dessa signaler min kropp i ett slags alarmläge.

Inom psykologin används begreppet haptiskt för att beskriva det mentalt utvidgade känslosinne som ansvarar för helhetsupplevelsen av att leva och agera i ett rum. Psykologen James J. Gibson intresserade sig för perceptuella system. Han talade om det haptiska sinnet som en sammankopplande länk mellan synförnimmelser och känsloförnimmelser vilka tillsammans skapar information och kunskap både om omgivningen och den egna kroppen. ${ }^{2}$

Skolans rumsliga utformning tycks ställa frågan: vem är starkast mentalt och fysiskt? Den säger också att rummen behöver skyddas från de människor som befolkar dem.

När skolan diskuteras i media är nästan alltid den fysiska, materiella och rumsliga dimensionen frånvarande. Det är som om skolans byggnader och rum anses vara neutrala scenografier som inte påverkar någon och att allt som är väsentligt sker inuti de människor som befolkar dem. Skolor, myndigheter, journalister och politiker fokuserar på Pisaresultat, organisation och administration. Pedagogernas viktiga roll understryks gång på gång vilket leder till att de får bära ett enormt ansvar för elevernas kunskaper, utan att få stöd av skolans fysiska miljö som istället ofta motverkar pedagogernas visioner kring lärande och samarbete. Samtidigt som diskussioner om pedagogernas roll för resultat och betyg pågår krymper kvadratmetrarna på barnens skolgårdar ${ }^{3}$ och tillfälliga baracker byggs istället för riktiga skolhus. ${ }^{4}$

Vad gör skolan som plats med människors kroppar, koncentration och uppmärksamhet? Brian Massumi beskriver människans uppmärksamhet och perception som spridd runtomkring oss i rummet och inte som ensidigt riktad och fokuserad. 'Sensationen 
är ett stadium där aktion, rum, perception och tanke är intensivt, performativt blandade.' 5

\section{Intervjuer med barn}

Bland alla experter som uttalar sig om skolan finns mycket sällan pedagoger och barn. Särskilt ovanligt är det att höra barn berätta om hur de upplever sin vardag i skolan. För några år sedan intervjuade jag några barn för ett radioprogram. Min tanke var från början att intervjua dem kring hur de uppfattade regler i skolan. Vilka regler ansåg de vara begripliga, användbara eller missledande? Men när jag under några dagar lät barnen vara mina guider skiftade mitt fokus sakta över till att mer och mer handla om hur skolans platser påverkade barnen. Jag upptäckte att det var svårt att avgöra vad som påverkade barnens beteenden mest: lärarnas regler eller skolans platser? I matsalen var barnen tvungna att äta lunch på tjugo minuter eftersom platsen var så liten och klasserna behövde avlösa varandra. Eftersom de skulle hinna äta upp på så kort tid behövde pedagogerna be barnen att inte prata med varandra under måltiden, utan att bara koncentrera sig på att äta. Enligt mina erfarenheter och iakttagelser är detta en mycket vanlig situation på många skolor i Sverige.

Senare, under vår rundvandring på skolgården blev det tydligt hur sammanflätade barnens lekar, konflikter och samtal var med de platser som skolan erbjöd men också hur pedagogernas regler steg ur olika brister på dessa platser. Fabian, nio år, guidade mig runt på skolområdet. Han tyckte att vi skulle börja vid 'Slagsmålsrinken' (fotbollsplanen) och berättade: 'Det är där alla börjar bråka, slå varandra. Så har fröknarna kommit på att man får rött kort om man gör något dumt. Man får gå av plan. Sen får man inte gå in på plan förrän nästa rast. Är man straffad en gång är det lätt att man blir gripen igen och så fungerar det bara. Hela världen är som en stor fotbollsplan. Och så har vi tre basketplaner. Och där borta finns en massa Kingplaner. Vi kan också gå till den stora klätterställningen. Där brukar de stora barnen putta ner varandra och... det är där det brukar hända. Någon bryter benet eller landar på armen. Jag tycker man borde ha fler övervakningskameror speciellt härute på skolgården. De stora börjar 
slåss och ... de gör det när inte rastvakterna är ute. De äldre tror att det är deras skolgård.' 6

Min upplevelse av skolgårdar är att de oftast är utrustade med aktiviteter som går ut på att barn ska sporta och tävla. Sällan erbjuds där möjligheter till konstnärligt arbete och ofta saknas kollektiva förslag i utemiljön som uppmuntrar till kreativ problemlösning och samarbete.

I boken Övervakning och straff skriver Michel Foucault att övervakningens arkitektur 'i varje stund ska övervaka vars och ens beteende, uppskatta, belöna det eller bestraffa det, mäta egenskaper och förtjänster. Disciplinen kräver ibland en sluten miljö, skapandet av en specifik plats som inte har något samband med andra platser och som är sluten om sig själv.'7

Kombinationen av att skolan är en relativt sluten institution med en miljö som är så präglad av fysisk och psykologisk konkurrens, tror jag är en av flera bidragande orsaker till mobbning, psykisk ohälsa och inlärningssvårigheter.

I min intervju bad jag också många olika barn på denna skola att rangordna det de tyckte att de lärde sig mest. Det genomgående svaret de gav som det viktigaste skolan skulle lära dem var 'beteende'. Ämneskunskaper var enligt dem av mindre betydelse och kom längre ned i ordningen.

'Vi lär oss att läsa och skriva. Engelska och så där. Men det vi lär oss mest är hur vi ska uppföra oss. Att man ska vara snäll och så' sa Sandra, nio år. Hon fortsatte: 'Ser du de där bänkarna där borta? Dörren där längst ditåt där finns ett hörn och där brukar jättemånga bli mobbade. För där ser ingen fröken. Det hände med Kalle i min klass. Han är alltid jätterädd för tre killar nu. Alltid när han ser dem springer han iväg. De hade puttat honom och slagit honom i ryggen. Då måste man ju säga till en fröken men då säger de: om du säger till en fröken så kommer jag att slå dig ännu mer.' När jag frågar Sandra vad hon tycker man ska göra åt det här svarar hon: 'Jättemånga tycker ju det är bra att säga till fröken. Men de lyssnar ju inte och då försöker några säga till föräldrar. Fast vad kan de göra? Jag tycker det är bra med övervakningskamera. Fast några vill ju ha privatliv.' 8 
Många barn gav, oberoende av varandra, bilden av skolan som en slags uppfostringsanstalt där den mesta tiden gick åt att belöna och straffa beteenden. Att det inomhus verkade råda en ganska strikt övervakning medan skolgården beskrevs som en laglös plats där de istället kände sig övergivna av de vuxna.

Om fysiska platser skapar både identitet och handling, kan pedagoger och skolutvecklare i större utsträckning förflytta sitt fokus från varje individ till skolans miljöer? Elisabeth Nordin Hultman skriver om vikten av att ifrågasätta uppdelningen mellan en "inre värld" och en "yttre verklighet". Att som pedagog ställa frågan: var blir barnet koncentrerat, okoncentrerat, våldsamt eller stillsamt? Istället för att fråga vem som är våldsam eller stillsam. ${ }^{9}$ En människas identitet går aldrig i repris utan måste varje gång, i varje situation skapas på nytt. Bronwyn Davies beskriver gränslandet mellan identitet och sammanhang: 'Identiteten är singulär, det vill säga vi blir 'nya' varje gång vi träder in i ett nytt rum och sammanhang. Poststrukturell diskurs skapar en förflyttning från självet som ett substantiv (och på så sätt stabilt och relativt fixerat) till självet som ett verb, alltid i en process...'

\section{Klassrummets ämnesdidaktiska potential}

Hur understöder ett standardklassrum pedagogers och elevers lärprocesser? Ämnesdidaktiskt skulle pedagoger kunna använda sig av många rumsliga idéer genom att utforma klassrum och skolbyggnader som tar hänsyn till människors sinnliga förmågor att relatera till estetik, sociala aspekter och till hur barn lär sig olika ämnen.

Går det att fysiskt bygga ett ämne utifrån idén att gränsen mellan den inre och yttre verkligheten inte är separerad? Om det ska bli möjligt att utforma rum som i högre utsträckning understöder lärprocesser behöver vi bli mer uppmärksamma på barns egna strategier för lärande så att rummen kan bli effektiva och underlätta i att skapa fokus, koncentration och intresse. Detta både för att slippa gå pedagogiska omvägar och för att elevernas nyfikenhet ska kunna växa och inte avta. Hur skulle till exempel ett naturvetenskapligt eller matematiskt klassrum kunna se ut för att verkligen understödja de begrepp som barnen ska undersöka och förstå? 
I forskningsprojektet 'Det magiska språket' ${ }^{\text {II }}$ på Stockholms Universitet stod iakttagandet av förskolebarns egna strategier för att lära sig läsa och skriva i fokus. Projektet handlade inte om att barn ska lära sig läsa i tidigare åldrar utan om att vi ville lära oss mer om hur mänskligt skrivande börjar och om hur förskolan skulle kunna fånga upp och stimulera små barns stora nyfikenhet till skrivande och läsande.

Ett av många projekt som barnen drev helt självständigt på förskolan var att tillverka böcker. De visade sig vara ganska experimentella, associativa berättelser och ofta uppfann de dessutom helt nya genrer av böcker. Till exempel skapade de en 'blåsbok' med sugrör i eller en 'kännbok' där sidorna bestod av sandpapper med olika grovkornighet. Barnens arbete var också alltid i allra högsta grad beroende av möjligheten att kunna arbeta tillsammans.

En annan observation i projektet rörde det vågformiga skrivande som små barn ägnar sig åt. Vi hade många gånger tidigare lagt märke till att barn i 2-5 års åldern skriver på detta vis. Blad efter blad, sida efter sida fylls med vågor, men vi hade aldrig frågat oss varför.

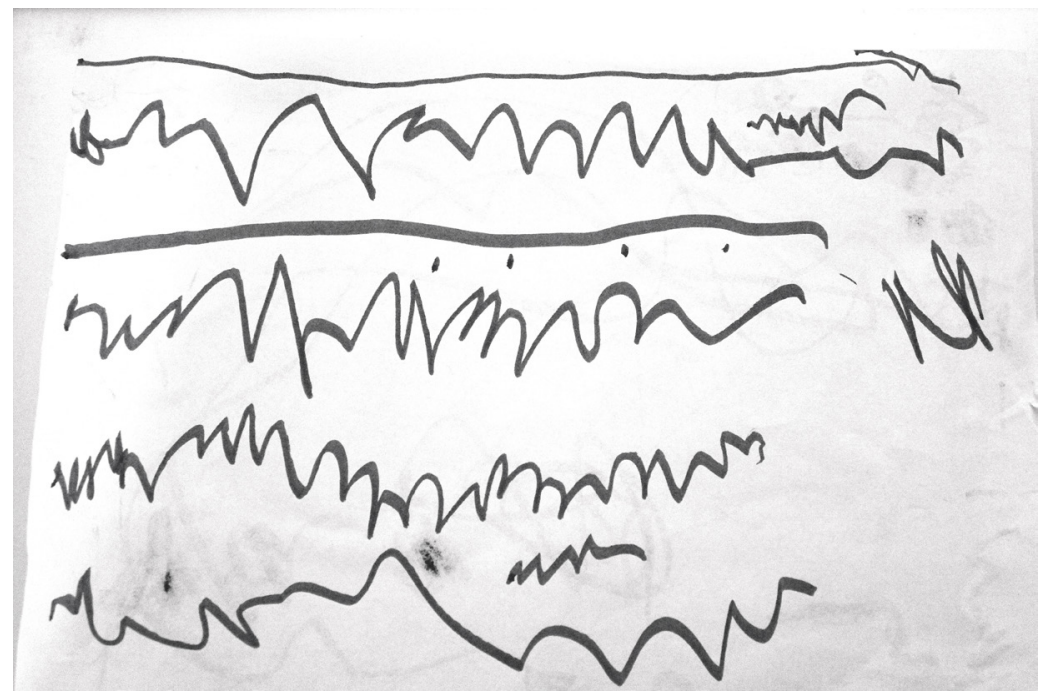

Bild 2a. Vagskrift. Copyright författaren. Publicerad med CC BY-licens. 
Spåren på pappren som barnen lämnade efter sig, och som tusentals små barn över hela världen lämnar efter sig dagligen, påminde oss om ett EKG. Ett hjärtats skrift. Vi hittade ett samband i en beskrivning av kalligrafiskt skrivande:

'Kalligrafiskt skrivande visar på rörelser, rörelser i hjärtat/hjärnan och rörelser i världen. Att skriva handlar om att förena hjärtats rörelser med världens rörelser. En del av konsten att hantera penseln handlar alltså om att minska avståndet mellan värld och hjärta. Penseln fungerar inte här som ett verktyg för ett medvetet uttryck, utan som en slags seismograf som känner av världens och hjärtats vibrationer och för ned dem på papper, silke eller bambu. Hjärtat är en öppning känslig för naturens rörelser; det utvidgas och dras samman ihop med naturens rörelser och hand/penseln vickar till svar. Hjärtat är i sanning det som rör sig mitt i.' ${ }^{\text {I2 }}$

Hur skulle ett rum kunna formas utifrån de strategier vi sett vara så viktiga för barnens intresse för skrivande: linjens puls, hjärtats skrift, kärleken till boken och det täta samarbetet med en kamrat?

Följande experiment skapades för barn i fem och sexårsåldern på en förskola, men det kunde lika väl kunna ha ägt rum på en skola. En av projektets generaliserbara allmändidaktiska idéer blev att låta observationer av barns strategier för lärande inom olika ämnen vara med och påverka utformningen av klassrummet. På så vis kan estetiska, fysiska dimensioner av ämnet mötas och undersökas kollektivt och sinnligt för att på bästa sätt skapa en intensitet $\mathrm{i}$ uppmärksamheten.

För att sudda ut eller i alla fall minska gränser mellan individer, ämnesdiscipliner, tecken, hjärta, hand och rum - att låta språket vara det som är mitt i, skapade vi ett 'ark' som gick att kliva in i. Vi slog in barnens vanliga läsrum helt och hållet i papper så att det skulle inspirera till många olika sätt att skriva, berätta, associera och samarbeta.

Gilles Deleuze och Felix Guattari har utvecklat idéer om 'striated spaces' och 'smooth spaces'. ${ }^{\text {I3 }}$ Striated spaces förstår jag som statiska, mätbara, tydligt organiserade platser medan 'smooth spaces' är platser fyllda av variation och förväntan. Smooth spaces innehåller öppningar för det okända, för händelser som ingen tidigare har erfarit. De rum vi befinner oss i är ofta en blandning 


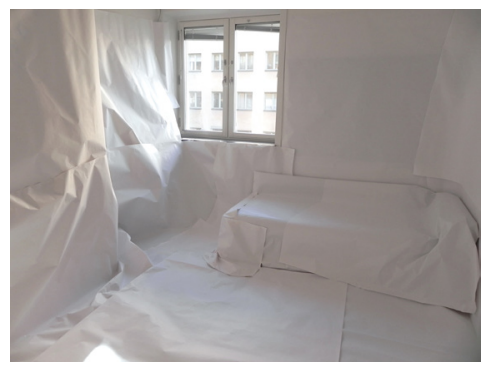

Bild 2b. Pappersrum. Copyright författaren. Publicerad med CC BY-licens.

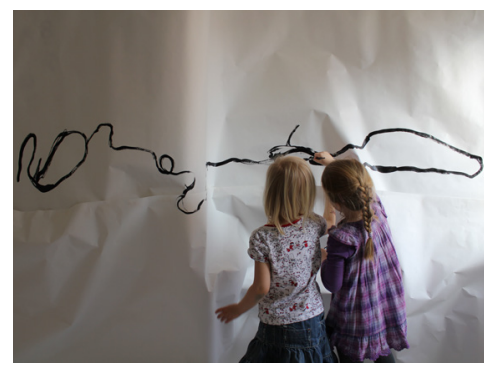

Bild 2d. Linje. Copyright författaren. Publicerad med CC BY-licens.

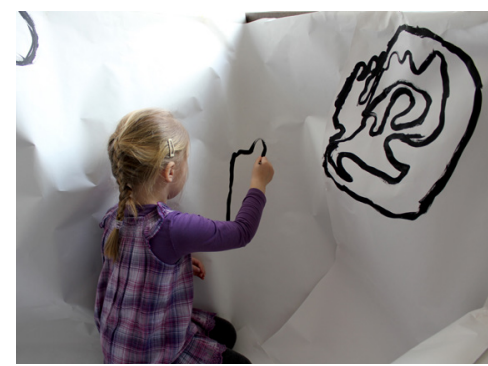

Bild 2c. Tecken. Copyright författaren. Publicerad med CC BY-licens.

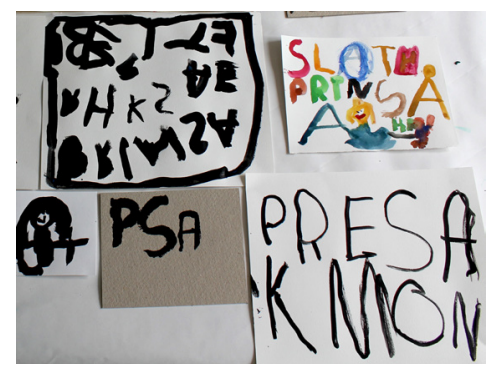

Bild 2e.Experimenttext. Copyright författaren. Publicerad med CC BY-licens.

av de båda. Det kan möjligen beskrivas som en slags skala som går mellan hur slutet eller öppet ett rum kan bli för att ta emot och föda fram nya tankar och att vi i så fall kan välja var på den skalan vi borde placera oss som pedagoger eller konstnärer.

I pappersrummet skapade barnen tecken, bokstäver, abstrakta former, bilder och bokstäver som förvandlades till bilder. Bokstaven 'S' blev en hund med kropp och ben. De undersökte hur linjer förändrades beroende på papprets bucklighet/släthet och lyssnade uppmärksamt på de starka ljuden som uppstod. Ibland gick de in i en gemensam muntlig och bildligt figurativ, konventionell saga som tog form genom långa associativa kedjor. De växlade mellan att berätta tillsammans, måla tillsammans och att försjunka i individuella experiment. De vandrade mellan det abstrakta och 
det figurativa vilket gjorde en utforskande processen väldigt långvarig. Ett slags flytande tillstånd mellan semiotiska möjligheter verkade hålla begäret och koncentrationen levande. Rummets utformning men också pedagogens närvaro stöttade den kreativa processen genom att följa den noggrant; iaktta, assistera, ställa frågor och dokumentera.

Experimentet blev startpunkt för en lång period där barnen fortsatte att skriva berättelser utifrån de ord och sagor som uppstått i rummet. I projektet prövade vi oss fram genom att arrangera många olika zoner för läsande och skrivande - platserna skulle göra det omöjligt att inte vilja börja skriva, de skulle vara 'oemotståndliga zoner för skrivande'. Platserna kunde se väldigt olika ut och omfattade en rad olika verktyg och uttryck, men de hade gemensamt att den estetiska utformningen skulle vara stark för att upphöja barnens sinnliga förnimmelser, entusiasm och skrivimpulser. Ett av projektets bidrag till barnens läs - och skrivutveckling blev att uppmuntra skrivexperiment och att försätta (omsluta) barnen i lekfulla rum och tillstånd av skrivande, att skapa situationer där de kunde befinna sig mitt i skrivandet och berättelsen. Poeten Inger Christenssen skriver:

'Det inträder snarare ett tröskeltillstånd där språk och värld uttrycker sig med hjälp av varandra. Världen som har sin naturliga förlängning i språket kommer till medvetande om sig själv, och språket som har sin bakgrund i världen, blir till en värld i sig, till en ständigt mer utvidgad värld. På det viset skulle man kunna säga att man i diktandet försöker producera något som man redan själv är en produkt av/... / tingen försvinner in i skuggan av varandra och sig själva men dikterna vänder tillbaka till ljuset med ett återsken av dessa skuggor.' ${ }^{4}$

I det skrivande rummet blev det tydligt att barnens intensiva experimenterande med tecken; bokstäver, ord och teckningar relaterade till platsens karaktär och till kalligrafins estetik och poesi, där människan genom sitt skrivande blir en slags seismograf åt världen.

En didaktisk skicklighet som går att utveckla är att spåra varje ämnes estetiska dimensioner och att försöka gestalta dem i skolans rum. Att ta större hänsyn till att det som omger oss, skolgårdar och klassrum, också är det som samtidigt är inuti oss. 
Foto:

Alla fotografier är tagna av Ebba Theorell. Bilderna 2 a, b, c, $\mathrm{d}$, e är fotograferade inom ramen för forskningsprojektet "Det magiska språket" vid institutionen för Barn- och ungdomsvetenskap, Stockholms Universitet

\section{Slutnoter}

I. Roos, C., Elam, K. \& Foultier, A.P. 20I2, s.78. Ord i tankar och rörelse.

2. Gibson, J. I969. Vara sinnen som perceptuella system.

3. Magnusson, M., \& Delaryd, C. 20I I. Skolgårdarna krymper i Stockholm, Svenska Dagbladet, 6 februari.

4. Gray,Ak., Moshél, D., Fungdal, L., Lindblom, L., Tiliander, J., Johansson, M., Sköld, L., \& Irving, A. 20I 3. Fem år i barackskola är en evighet för våra barn, Dagens Nyheter, 27 April.

5. Massumi, B. 2002, s. 97 (min översättning ). Parables for The virtual.

6. Theorell, E. 20I3, s.IоI. Mårtens, Y. (Red.) Barnet i dokumentären.

7. Foucault, M. 2009, s.I45. Övervakning och straff.

8. Theorell, E. 20I3, s.102-IO3.

9. Nordin Hultman, E. 2006, s. I70 -I7I. Pedagogiska miljöer och barns subjektsskapande.

Io. Nordin Hultman, E. 2006, s. I7 I.

I I. 'Det Magiska Språket' - Små barns relationer till språket, läsande och skrivande. Projekt vid Stockholms universitet, Barn och ungdomsvetenskapliga institutionen. https://www.buv.su.se/forskning/forskningsprojekt/projekt-inom-förskoledidaktik/det-magiska-språketsmå-barns-relationer-till-språket-läsande-och-skrivande-I.93759

I 2. Olsson, L.M., Dahlberg, G., Theorell, E. 20I 5. Discplacing identity-placing aesthetics: early childhood literacy in a globalized world I3. Unga, J. 20I3. DET ÄR EN SPRICKA I ALLT, DET ÄR SA LJUSET KOMMER IN... Matematik och förskolebarns experimenterande och potentialitet 
I4. Cristenssen, I. 20I I, s. 29-32. Hemlighetstillståndet.

\section{Referenser}

Cristenssen, I. 20 I I. Hemlighetstillståndet. Stockholm: Ariel förlag.

Dahlberg. G., \& Olsson, L.M., \& Theorell, E. 2015. "Displacing Identity - Placing Aesthetics Early Childhood Literacy in a Globalized World." Fabulous monsters: alternative discourses of childhood in education. Special Journal Issue of Discourse: Studies in the Cultural Politics of Education

Danius, S., \& Sjöholm, C., \& Wallenstein, S-O. 20I2. Aesthesis Estetikens historia del I. Stockholm: Stiftelsen bokförlaget Thales.

Foucault, M. 2009. Övervakning och straff. Lund: Arkiv förlag.

Gibson, J. I969. Vara sinnen som perceptuella system. Stockholm: KL Beckmans tryckerier AB.

Lysen, F., \& Pisters, P. 20I 2." The smooth and the striated”. Deleuze Studies, 6(I), $I-5$.

Gray,Ak.,Moshél,D.,Fungdal,L.,Lindblom,L.,Tiliander,J.,Johansson, M., Sköld, L., \& Irving, A. 20 I 3. Fem år i barackskola är en evighet för våra barn, Dagens Nyheter. 27 April. Läst från: https://www. dn.se/debatt/fem-ar-i-barackskola-ar-en-evighet-for-vara-barn/

Magnusson, M. \& Delaryd, C. 20II. Skolgårdarna krymper i Stockholm, Svenska Dagbladet, Stockholm, 6 februari. Läst från: https://www.svd.se/skolgardarna-krymper-i-stockholm

Marks, L.M. 2002. Touch: Sensuous Theory and Multisensory Media. Minneapolis: University of Minnesota Press.

Mattson, H. \& Wallenstein, S-O. (Red.) 20Iо. Deleuze och mångfaldens veck. Stockholm: Axl books.

Massumi, B. 2002. Parables for the virtual. London: Duke University press.

Nordin Hultman, E. 2006. Pedagogiska miljöer och barns subjektsskapande. Stockholm: Liber.

Roos, C., Elam, K., \& Foultier A.P. 20г 2. Ord i tankar och rörelse. Stockholm: Dans och cirkushögskolan. 
Sand, M. 2008. Konsten att gunga. KTH. Stockholm: Axl Books.

Theorell, E. 20I3. 'Hela världen är som en fotbollsplan'. I Barnet $i$ dokumentären. Y. Mårtens (red.) Stockholm: Stockholms Dramatiska Högskola.

Unga, J. 20I3. DET ÄR EN SPRICKA I ALLT, DET ÄR SÅ LJUSET KOMMER IN... Matematik och förskolebarns experimenterande och potentialitet. Licentiatuppsats. Stockholm: Stockholms universitet. 


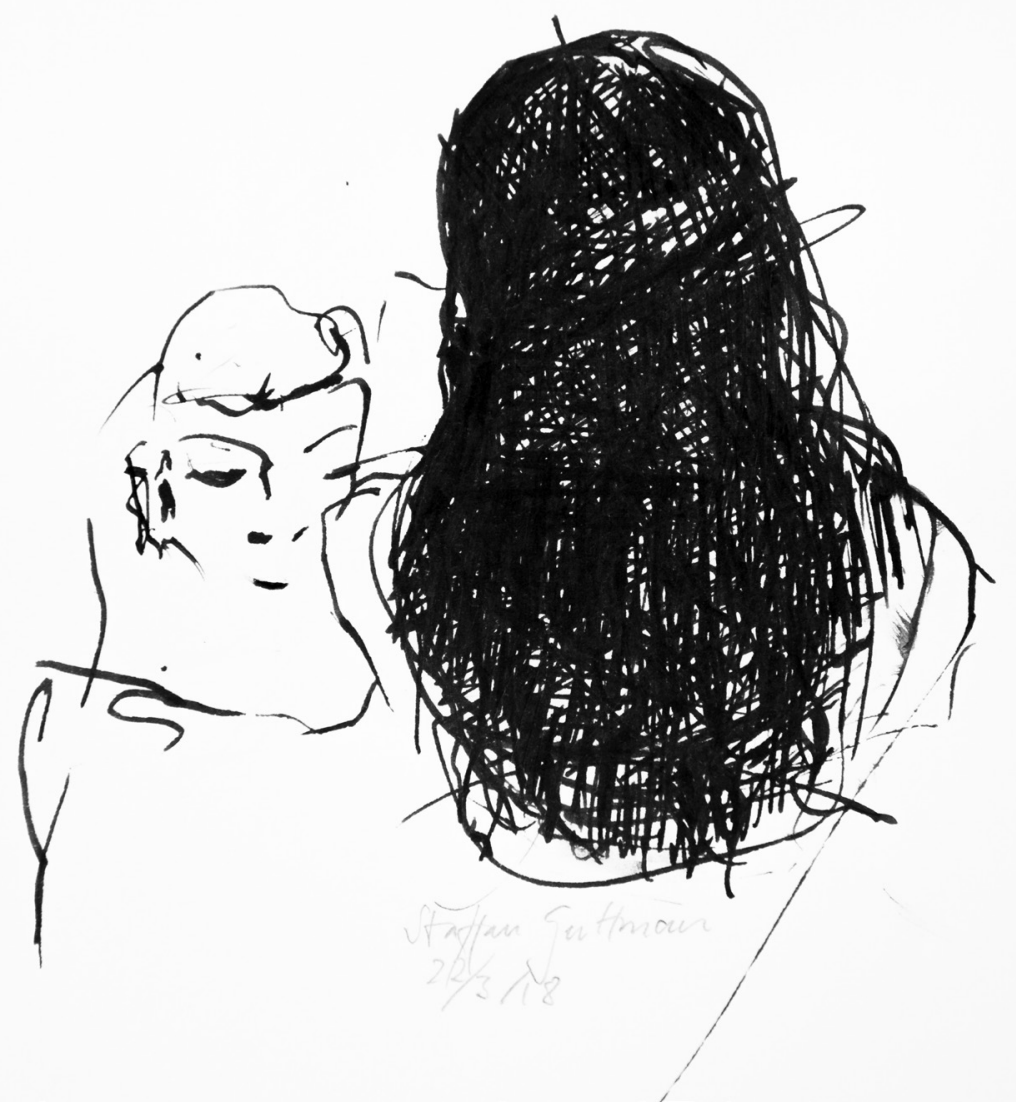

Bild 6. Estetiskt ämne Dans. Bläckteckning. Den här bilden är publicerad med CC BY-licens, med tillstånd av upphovsrättsinnehavaren tecknaren Staffan Guttman. 
